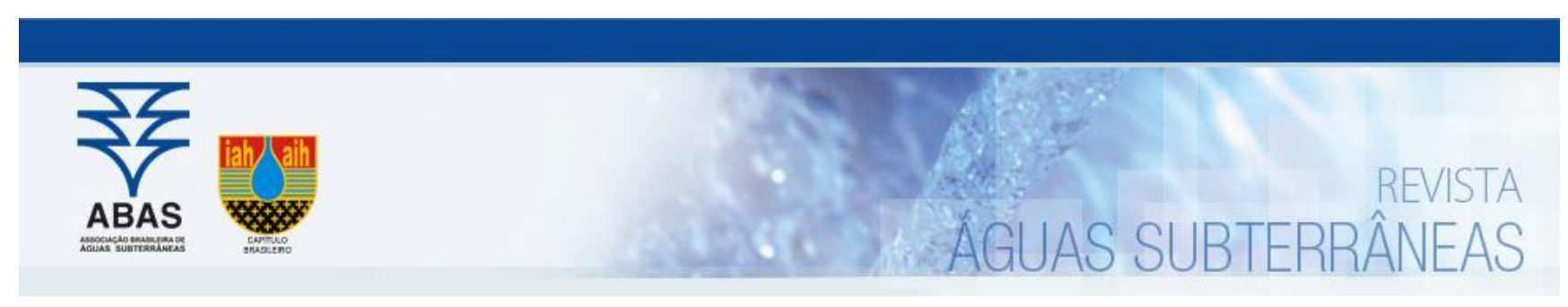

Artigos

\title{
Potabilização de água salobra por meio de um dessalinizador solar portátil com refletores de radiação integrados
}

\section{Brackish water potabilization through a portable solar still with integrated radiation reflectors}

\author{
Adriano Oliveira da Silva1; Yohanna Jamilla Vilar de Brito1; Vanessa Rosales Bezerra1; Geralda Gilvânia Cavalcante de \\ Lima$^{1}$; Keila Machado de Medeiros²; Carlos Antônio Pereira de Lima1 ${ }^{\circledR}$ \\ 1 Universidade Estadual da Paraíba (UEPB), Departamento de Engenharia Sanitária e Ambiental (DESA), Campus de \\ Campina Grande - PB \\ 2 Universidade Federal do Recôncavo da Bahia (UFRB), Centro de Ciência e Tecnologia em Energia e Sustentabilidade \\ (CETENS), Campus de Feira de Santana - BA.
}

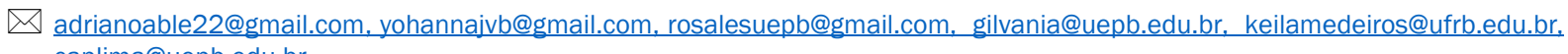
caplima@uepb.edu.br

\section{Palavras-chave:}

Escassez hídrica.

Dessalinizador solar.

Energia solar.

Potabilidade da água.

\section{Keywords:}

Water scarcity.

Solar desalter.

Solar energy.

Water potability.

\begin{abstract}
Resumo
Um dessalinizador solar portátil com refletores de radiação integrados foi utilizado com o intuito de obter uma água tratada conforme os padrões de potabilidade para o consumo humano. Este trabalho teve como objetivo analisar o desempenho térmico do dessalinizador solar para produção de água dessalinizada e a qualidade físico-química da água antes e após o processo de dessalinização. A água salobra foi coletada no poço no Sítio Poço de Pedra, no município de Juazeirinho - PB. Foi observado uma produção máxima de água potável de $2730,8 \mathrm{~mL} \mathrm{~m}^{-2}$ dia-1 $^{-1}$ para um índice de radiação solar média de $660,42 \mathrm{~W} \mathrm{~m}^{-2}$. Os resultados obtidos das análises físico-químicas das águas salobra e dessalinizada apresentaram reduções no teor de cloreto de $99,72 \%$, o sódio de $99,88 \%$ e nos sólidos totais dissolvidos de $99,73 \%$ após o processo de dessalinização, atingindo valores de acordo com os padrões de potabilidade exigidos pela Portaria do Ministério da Saúde vigente no país.

Abstract

A portable solar stil with integrated radiation reflectors was used to obtain treated water with human consumption standards. This article aimed to analyze the thermal performance of the solar still to produce desalinated water and the physical-chemical quality of the water before and after the desalination process. The brackish water sapled in the well at Poço de Pedra Farm, in the municipality of Juazeirinho - PB. Maximum drinking water production of $2730.8 \mathrm{~mL}$ $\mathrm{m}^{-2}$ day-1 observed for an average solar radiation index of $660.42 \mathrm{~W} \mathrm{~m}^{-2}$. The results obtained from the physical-chemical analysis of brackish and desalinated waters showed reductions in the chloride content of $99.72 \%$, sodium of $99.88 \%$ and total dissolved solids of $99.73 \%$, reaching values in accordance with the standards of potability required by the Ministry of Health.
\end{abstract}

Recebido em: 24/06/2020.

Aprovado em: 11/08/2020.

DOI: http:/dx.doi.org/10.14295/ras.v34i3.29923

\section{INTRODUÇÃO}

As tecnologias de dessalinização de água assistida por energia renovável estão se tornando atraentes como uma solução para crise da escassez de água doce. 0 crescimento populacional, o desenvolvimento industrial e agrícola juntamente a poluição e contaminação das águas, as quais são descartadas se não houverem tratamento adequado, resultaram no aumento da taxa de consumo de água (MOLLAHOSSEINI et al., 2019).
O fornecimento de água potável é o maior desafio das comunidades rurais da região semiárida do Brasil (OLIVEIRA et al., 2017) que são caracterizadas pela disponibilidade limitada e irregular de recursos hídricos (MARINHO et al.,2012). A perfuração de poços é uma alternativa para suprir a escassez de água, no entanto a água encontrada nos poços geralmente é salobra ou salina devido à formação da rocha cristalina na maior parte do semiárido brasileiro, correspondendo cerca de 80\% do território (SILVA e SHARQAWY, 2020). 
De maneira a solucionar esta problemática, sucessivas tecnologias de dessalinização têm sido utilizadas para a potabilização de águas salinas e salobras, tais como: osmose inversa, eletrodiálise, destilação multiestágio, destilação multiefeito, destilação solar, etc.

A dessalinização é uma técnica que consiste em tratar a água

salobra e ou salina, na qual remove os sais, tornando a água adequada/própria para irrigação ou abastecimento. Além disso, os processos de dessalinização por osmose inversa, eletrodiálise, destilação multiestágio e destilação multiefeito implicam em um dos maiores gasto de energia elétrica e/ou térmica na área de tratamento de água e, portanto, regiões que dispõem de pequena capacidade de energia têm uma considerável dificuldade para implantar essas operações (FONSECA et al., 2020).

Em contrapartida, as zonas descentralizadas, com pouca infraestrutura e carentes de água potável, como o semiárido nordestino, geralmente possuem elevada incidência de radiação solar. Essas características aparentam sugerir como alternativa a aplicação de processos de dessalinização por energia solar, pois demonstram condições apropriadas para a implantação desses métodos alternativos que são barreiras para os tradicionais (CAMPOS et al., 2019).

A dessalinização via energia solar evidencia ser uma técnica promissora para os problemas de escassez de água doce em comunidades isoladas, pois apresentam maior sustentabilidade a essa operação, por utilizar uma energia limpa e renovável para a potabilização da água, sendo assim uma solução composta tanto para a carência de água potável, quanto para os problemas energéticos e ambientais igualmente enfrentados.

Atualmente, os dessalinizadores solares de bandeja plana são equipamentos convenientes para a produção de água potável por sua fácil fabricação, além de ter baixo custo comparado a outros dessalinizadores solares. No entanto, esse dessalinizador solar apresenta um rendimento menor do que outros tipos de dessalinizadores solares. Por esta razão, pesquisadores buscam aumentar a eficiência e o desempenho desse tipo de dispositivo. Uma das modificações em sua configuração consiste na substituição da bandeja plana por uma bandeja subdividida em patamares, que é característica do dessalinizador cascata (BOUZAID et al., 2019).

O dessalinizador solar tipo cascata possui duas qualidades significativas para aumentar a eficiência e produção de água dessalinizada, sendo a estrutura inclinada com bandeja escalonada e um único canal de condensado para obter a água dessalinizada (ARUNKUMAR et al., 2019). De acordo Bouzaid et al. (2019), os dessalinizadores solares escalonados ainda com defletores têm maior produtividade em comparação aos dessalinizadores tipo bandeja, porque a placa absorvedora é feita em várias etapas, oferecendo profundidade mínima de água salobra.

Os dessalinizadores solares integrados a refletores são um dos mais eficientes para um bom comportamento térmico na produção de água dessalinizada. Os refletores externos ou in- ternos são modificações de baixo custo para aumentar a incidência de irradiação solar para o revestimento da bandeja e a água, proporcionando maior produtividade de água dessalinizada (OMARA; KABEEL e ABDULLAH, 2017).

Segundo Omara et al. (2016), a produtividade da água de des-

salizadores solares com espelhos refletores aumenta em cerca de $145 \%$ em relação aos modelos convencionais. Estahbanati et al. (2016) relataram que a instalação de refletores em todas as paredes laterais do dessalinizador, em comparação com um dessalinizador sem refletores, pode aumentar a produção de água dessalinizada no período de inverno, verão e ano inteiro em $65 \%, 22 \%$ e $34 \%$, respectivamente.

Neste contexto, o presente trabalho buscou analisar o desempenho térmico de um dessalinizador solar portátil do tipo ondular com refletores de radiação integrados para a produção de água dessalinizada e que atenda os padrões vigentes de potabilidade para o consumo humano.

\section{MATERIAL E MÉTODOS}

A construção do protótipo e os experimentos do dessalinizador solar foram realizados na cidade de Campina Grande - PB, situada a $126 \mathrm{Km}$ da capital João Pessoa, a $551 \mathrm{~m}$ acima do nível do mar, tendo como coordenadas $7^{\circ} 13^{\prime} 50^{\prime \prime}$ sul e $35^{\circ} 52$ '52" oeste, no Laboratório de Pesquisa em Ciências Ambientais - LAPECA, do Departamento de Engenharia Sanitária e Ambiental - DESA do Centro de Ciências e Tecnologia - CCT da Universidade Estadual da Paraíba UEPB.

\subsection{Dessalinizador solar}

O dessalinizador solar é constituído por uma placa absorvedora de calor que tem o formato ondular de composto de fibrocimento na sua confecção, de $6 \mathrm{~mm}$ de espessura, possuindo $1,43 \mathrm{~m}$ de comprimento e 0,543 $\mathrm{m}$ de largura, tendo uma área útil para dessalinização de $0,78 \mathrm{~m}^{2}$ e pintada de preto fosco para melhor absorção da radiação solar. Além disso, o dessalinizador possui uma cobertura de vidro de 3 $\mathrm{mm}$ de espessura e refletores de radiação de chapas de alumínio com dimensões de 0,704 m de comprimento e 0,545 $m$ de largura na parte superior e nas laterais possuem 1,49 m de comprimento e 0,55 $\mathrm{m}$ de largura cada.

Os materiais empregados no dessalinizador solar foram estabelecidos visando o maior custo-benefício, além de assegurar um bom isolamento, resistência à temperatura e durabilidade. Outro aspecto relevante foi a disponibilidade dos materias na região, com vistas a facilitar a construção do equipamento.

\subsection{Descrição do sistema}

O sistema foi alimentado por gravidade com uma vazão de 30,6 mL min-1 de água salobra na parte superior do dessalinizador operando em modo contínuo, percorrendo por toda a placa absorvedora. Com a irradiação direta e refletida para a placa absorvedora de calor através da cobertura de vidro inclinada, rapidamente a superfície da placa absorvedora é aquecida, transferindo o calor por meio de convecção para a água, provocando o aumento na taxa de evaporação. 0 vapor de 
água é condensado ao entrar em contato com a superfície interna da cobertura de vidro e, por meio da gravidade, a água dessalinizada escorre e é recolhida na parte inferior pela canaleta de coleta, conforme apresentado na Figura 1.

Figura 1 - Dessalinizador solar portátil tipo ondular com refletores

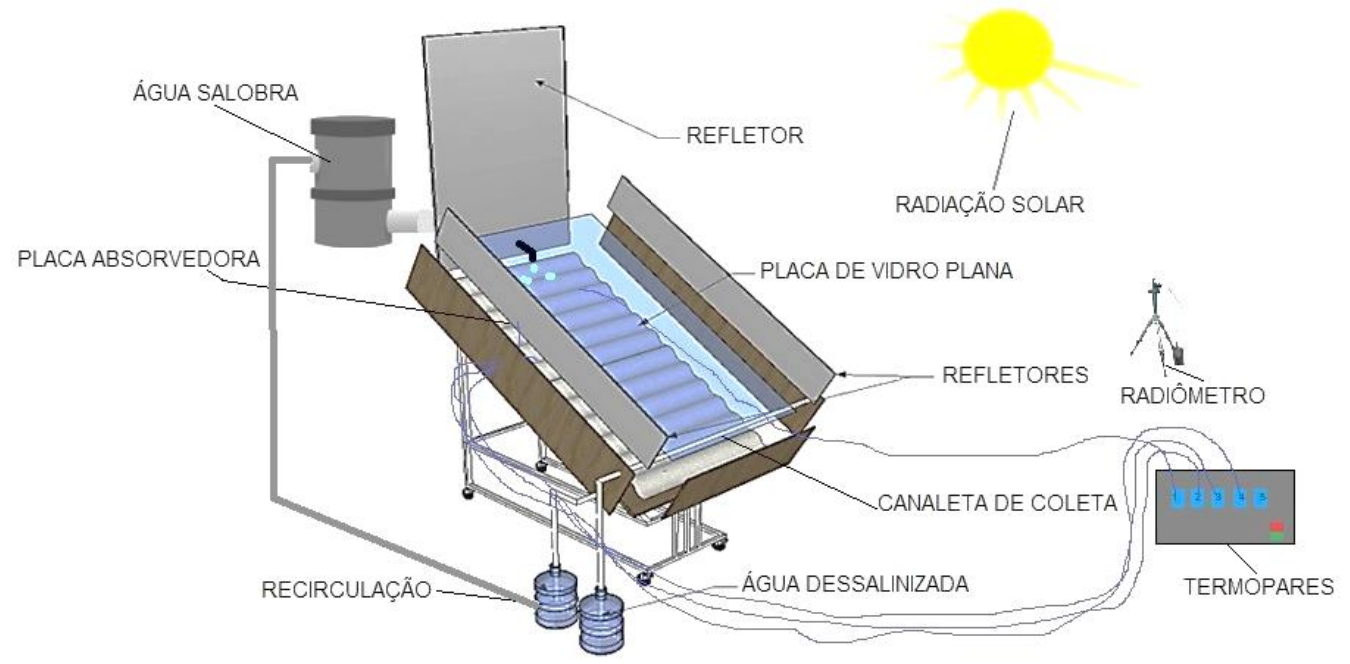

\subsection{Procedimento do ensaio e coleta de dados}

A água salobra foi coletada em um poço no Sítio Poço de Pedra, no município de Juazeirinho - PB. Esse poço foi selecionado por ser utilizado como fonte de abastecimento de água para consumo humano e animal na comunidade local.

Com o intuito de realizar o teste de desempenho do dessalinizador solar, foram realizados dois ensaios (experimento $1 \mathrm{e}$ experimento 2) em dias diferentes no período de março de 2020, em que houveram variação apenas das condições climáticas, iniciado às $07 \mathrm{~h} 00$ min e finalizado às $17 \mathrm{~h} 00 \mathrm{~min}$. A cada 30 minutos foi medido o volume da água dessalinizada obtida e no final o volume total, para a caracterização das propriedades físico-químicas e também calculada a eficiência térmica do dessalinizador.

Foram realizadas medições de temperatura na água salobra, no vidro, no isolante, na placa absorvedora do dessalinizador e também a temperatura ambiente, a cada 30 minutos, utilizando termopares do tipo PT-100 de ligas metálicas. A medição da radiação global foi efetuada de modo ininterrupto durante todo o funcionamento do dessalinizador por meio do radiômetro SL 20017957 da marca KIMO.

\subsection{Eficiência térmica}

Existem dois tipos de eficiência térmica para o dessalinizador solar: a eficiência horária e a eficiência diária. A eficiência horária reflete a razão entre o calor latente de vaporização de água médio gerado pela água produzida de hora em hora e a quantidade total de energia solar absorvida. A variação da irradiância solar durante o dia gera, obviamente, uma variação horária da eficiência térmica (RABHI et al., 2017).

A eficiência horária e diária pode ser obtida pelas Equações (1) e (2), respectivamente (EL-AGOUZ, 2014).
$\eta_{H}=\frac{(M * L) / 3600}{A_{v} * I(t)} * 100$

$\eta_{D}=\frac{1}{n} \sum_{n} \eta_{H} * 100$

onde, $M[\mathrm{~kg}]$ corresponde a produção horária de água, $L$ [W s $\left.\mathrm{kg}^{-1}\right]$ é o calor latente de vapor de água, $A_{v}\left[\mathrm{~m}^{2}\right]$ é a área de cobertura do vidro e $I(t)\left[\mathrm{W} \mathrm{m}^{-2}\right]$ é a intensidade de irradiação solar.

\subsection{Parâmetros para análise da água}

A eficiência do dessalinizador está relacionada a qualidade da água dessalinizada, visto que essa é a real finalidade do dessalinizador solar. Dessa forma, tanto a água salobra, como a água dessalinizada foram submetidas a testes para verificar alguns parâmetros físico-químicos que são determinantes segundo a legislação de potabilidade da água de acordo com a Portaria de Consolidação nº 005/2017 do Ministério da Saúde - MS (BRASIL, 2017).

As análises ocorreram nos laboratórios de Pesquisa em Ciências Ambientais e o de Referência em Tecnologias de Águas, ambos na UEPB. As metodologias utilizadas para obter todos os parâmetros físico-químicos das águas provenientes da alimentação e do destilado estão preconizadas no Standard Methods for Examination of Water and Wastewater (BAIRD, EATON e RICE, 2017). O Quadro 1 apresenta os parâmetros físico-químicos analisados juntamente com a metodologia utilizada. 
Quadro 1 - Parâmetros físico-químicos analisados e equipamentos utilizados

\begin{tabular}{|c|c|c|}
\hline Parâmetro & Unidade & Metodologia \\
\hline $\mathrm{pH}$ & adimensional & pHmetria \\
\hline Condutividade elétrica & $\mu \mathrm{Scm}^{-1}$ & Condutimetria \\
\hline Cor aparente & $\mathrm{uH}$ & Colorimetria \\
\hline Cloreto & $\mathrm{mg} \mathrm{Cl-L-1}$ & Titulometria - Mohr \\
\hline Dureza & $\mathrm{mg} \mathrm{CaCO}_{3} \mathrm{~L}^{-1}$ & Titulometria - EDTA \\
\hline Alcalinidade & $\mathrm{mg} \mathrm{CaCO} \mathrm{CL}^{-1}$ & Titulometria com indicador \\
\hline Turbidez & NTU & Nefelometria \\
\hline Sódio & $m g ~ \mathrm{Na}^{+} \mathrm{L}^{-1}$ & Fotometria de chama \\
\hline Potássio & $\mathrm{mg} \mathrm{K}^{+\mathrm{L}^{-1}}$ & Fotometria de chama \\
\hline STD & $\mathrm{mgL}^{-1}$ & Método instrumental \\
\hline
\end{tabular}

SDT $=$ Sólidos Totais Dissolvidos

\section{RESULTADOS E DISCUSSÃO}

\subsection{Desempenho térmico do protótipo do dessalinizador solar}

Com o intuito de avaliar o desempenho térmico e do volume de água dessalinizada, foram realizadas diversas medições de temperaturas nos principais componentes do dessalinizador. Simultaneamente, foi feito o acompanhamento das condições climáticas e dos níveis diários de radiação solar, observando parâmetros térmicos para este tipo de equipamento.

A Figura 2 apresenta as variações de temperatura interna da cobertura de vidro, temperatura da água, temperatura da placa absorvedora e a temperatura ambiente, e da radiação solar incidente em função do horário de operação do dessalinizador no experimento 1. Ao analisar os valores, é possível verificar o aumento gradativo dos perfis de temperatura até às $11 \mathrm{~h} 30 \mathrm{~min}$, onde os valores da temperatura interna da cobertura de vidro mantiveram-se inferiores às demais temperaturas, e isso de fato ocorre porque o vidro se encontra com uma temperatura inferior ao do vapor d'água, o que garante que ocorra o processo de condensação (AL-GARNI, 2012).

Figura 2 - Perfis de temperatura e radiação solar no experimento 1

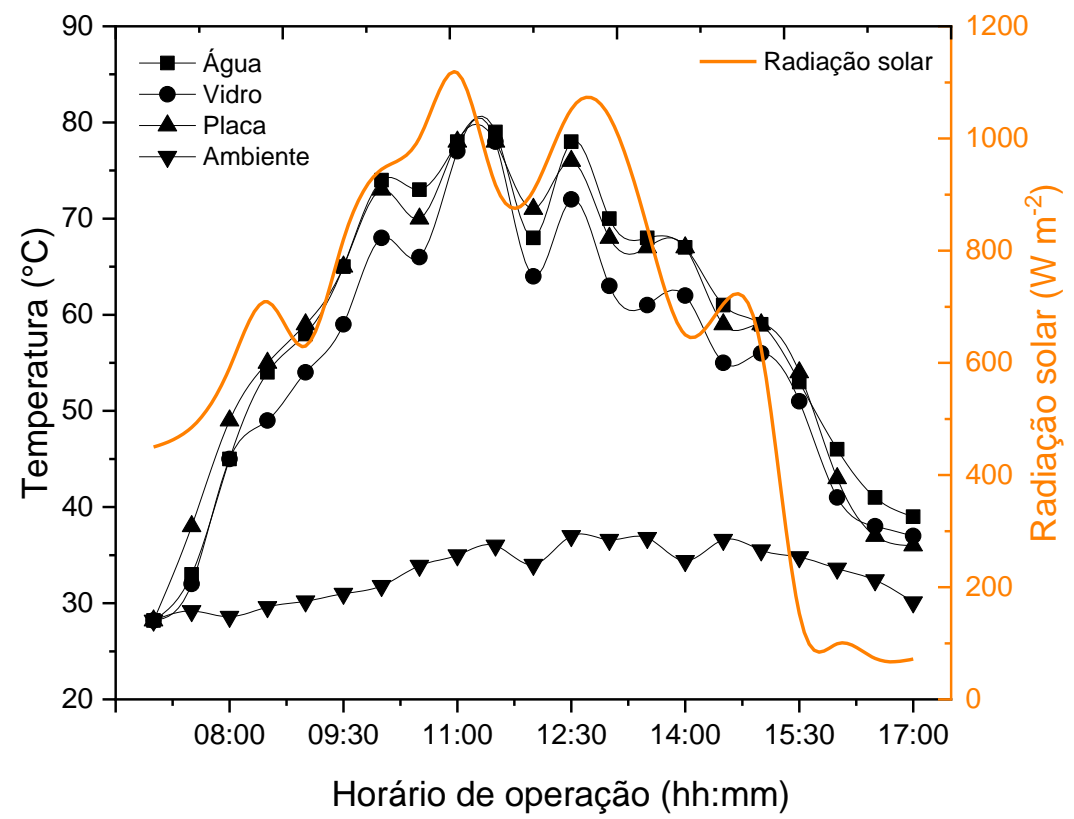

Ao longo do experimento, a temperatura da água salobra sofre variações. Inicia às $07 \mathrm{~h} 00 \mathrm{~min}$ com a temperatura de $28,2{ }^{\circ} \mathrm{C}$ e atinge maior temperatura às $11 \mathrm{~h} 30 \mathrm{~min}$, alcançando $79^{\circ} \mathrm{C}$, trinta minutos depois do momento de maior incidência de ra-

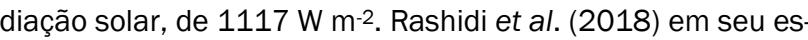
tudo relatou atingir a temperatura máxima da água salobra e temperatura ambiente $73{ }^{\circ} \mathrm{C}$ e $38{ }^{\circ} \mathrm{C}$, respectivamente, e intensidade de radiação solar de $943,5 \mathrm{~W} \mathrm{~m}^{-2}$ no dessalinizador solar inclinado modificado.

A Figura 3 exibe as variações de temperatura interna da cobertura de vidro, temperatura da água, temperatura da placa absorvedora e a temperatura ambiente em função da radia- 
ção solar incidente no dessalinizador no experimento 2. Os valores de temperatura interna da cobertura de vidro também se mantiveram inferior às demais temperaturas. Ao longo do experimento, a temperatura da água salobra também sofre variações e atinge maior temperatura às $12 \mathrm{~h} 00 \mathrm{~min}$, alcançando $82{ }^{\circ} \mathrm{C}$ no momento de maior incidência de radiação solar, $1144 \mathrm{~W} \mathrm{~m}^{-2}$. No trabalho de Mulftah, Sopian e Alghoul (2018) a temperatura da água salobra alcançou cerca de $62{ }^{\circ} \mathrm{C}$ no dessalinizador solar escalonado sem modificação, e após a modificação com adição de refletores a temperatura da água chegou a, aproximadamente, $70^{\circ} \mathrm{C}$. Portanto, no estudo realizado do experimento 2 foi obtido um valor superior de temperatura, resultando em uma maior produção de água dessalinizada.

Figura 3 - Perfis de temperatura e radiação solar no experimento 2

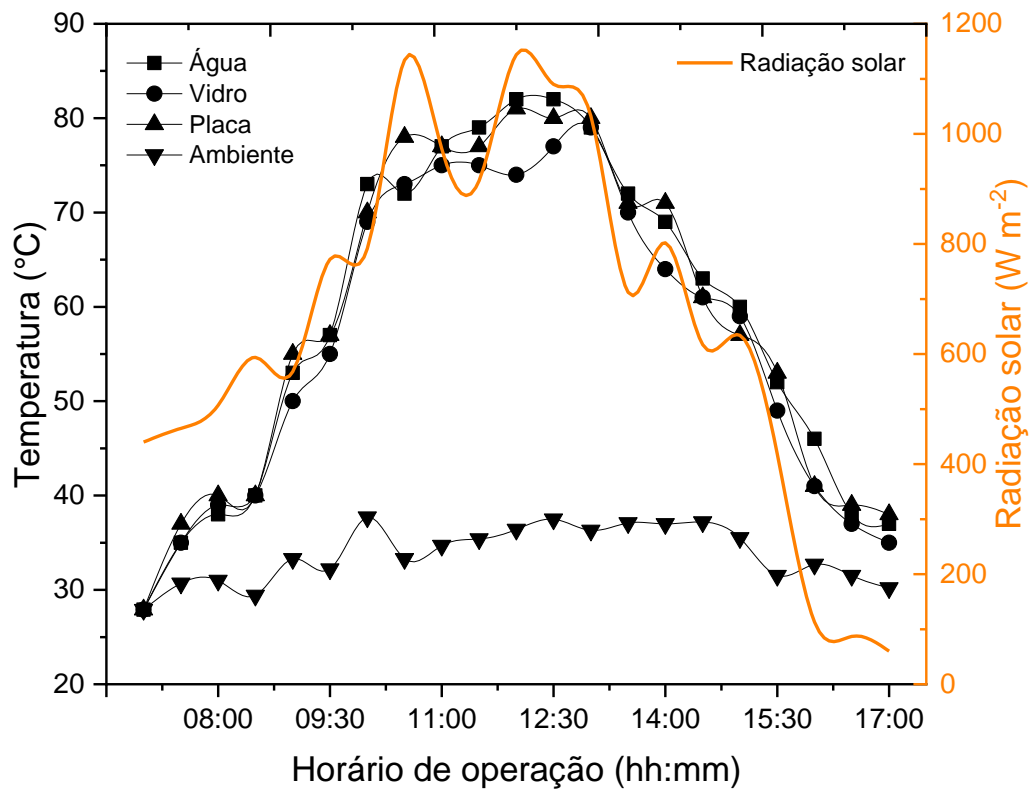

Observa-se que os perfis de temperatura no experimento $1 \mathrm{e}$ no experimento 2 acompanha a intensidade de radiação solar no dessalinizador, devido à decorrência da radiação solar direta e refletida no dessalinizador. 0 perfil da temperatura ambiente variou de $28,2{ }^{\circ} \mathrm{C}$ a $37{ }^{\circ} \mathrm{C}$ no decorrer do dia para o experimento 1 e $27,9{ }^{\circ} \mathrm{C}$ a $37,7^{\circ} \mathrm{C}$ para o experimento 2 , e os perfis de temperatura do vidro acompanharam o perfil da temperatura da água salobra durante todo o experimento. No estudo de Matrawy, Alosaimy e Mahrous (2015) com dessalinizador solar simples com um refletor inclinado, a temperatura ambiente correspondeu a $35^{\circ} \mathrm{C}$ e radiação solar a, aproximadamente, $1150 \mathrm{~W} \mathrm{~m}^{-2}$, valores semelhantes aos encontrados neste estudo.

\subsection{Produção de água dessalinizada}

A Figura 4 apresenta a variação da produção de água dessalinizada com o tempo de operação e em função dos perfis de temperatura da água, temperatura do vidro, temperatura da placa absorvedora e temperatura do ambiente. Observa-se no experimento 1 que o volume de água dessalinizada acompanha a variação das temperaturas da água, do vidro e da placa, onde há o acumulo gradativo da produção de água dessalinizada.

Com base nos valores obtidos, percebeu-se que durante o ensaio a temperatura do ambiente estava favorável ao experimento, apresentando valores acima da média de $31^{\circ} \mathrm{C}$ da região nordeste (INMET, 2019). Outro fato observado foi ausência de alterações bruscas de temperatura ao longo do dia, obtendo-se ao final uma temperatura média de $33,11^{\circ} \mathrm{C}$, influenciando diretamente no aumento da temperatura interna do dessalinizador, que é um fator importante no processo de dessalinização. E com isso, a produção de água dessalinizada acumulada durante o dia do experimento 1 foi de $2596,1 \mathrm{~mL}$ $\mathrm{m}^{-2}$. 
Figura 4 - Produção de água em função dos perfis de temperatura no experimento 1

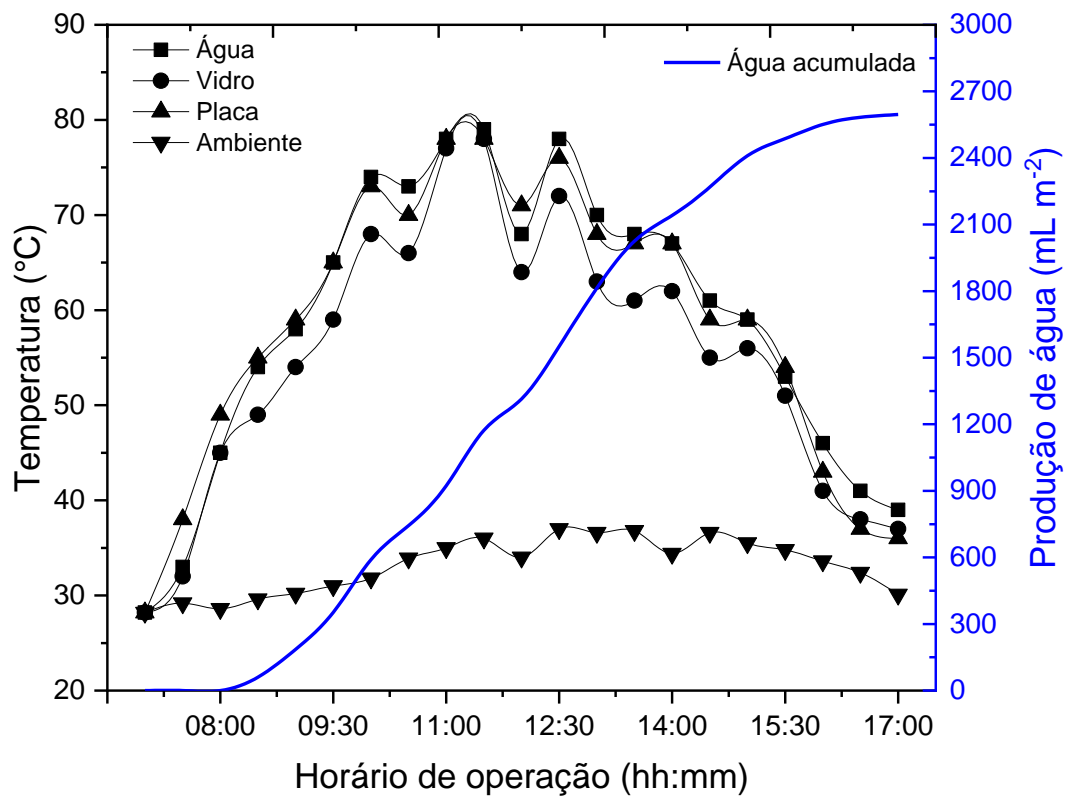

Na Figura 5 pode-se observar os valores de temperatura da água salobra do experimento 2 , em que o estudo desse parâmetro relaciona a radiação solar incidente sobre o dessalinizador com a capacidade do sistema de direcionar e conservar essa energia para aquecer a água salobra. Ao se analisar os valores obtidos de temperatura da água salobra e temperatura da placa absorvedora, percebeu-se que o comportamento do sistema, especialmente o da placa absorvedora, isolamento e vedação foram satisfatórios, pois a temperatura da água salobra elevou-se até às $12 \mathrm{~h} 30 \mathrm{~min}$, chegando ao ápice de $82{ }^{\circ} \mathrm{C}$, decaindo somente na última hora de medição, pois houve uma diminuição da radiação solar incidente em $94,49 \%$. Resultado mais próximo ao obtido no experimento 2 , foi retratado por Bouzaid et al. (2019) que estudaram um dessalinizador solar tipo cascata com defletores, em que a temperatura da água salobra e temperatura da placa absorvedora atingiram $72{ }^{\circ} \mathrm{C}$ e $74^{\circ} \mathrm{C}$, respectivamente.

Ao fim do período de análise se obteve uma temperatura mé- dia da placa absorvedora e da água salobra, respectivamente, de $58,61{ }^{\circ} \mathrm{C}$ e $58,66{ }^{\circ} \mathrm{C}$ para o experimento 2. Enquanto no experimento 1 as temperaturas médias da placa absorvedora e da água salobra foram de $58,58^{\circ} \mathrm{C}$ e $58,91^{\circ} \mathrm{C}$, valores próximos do experimento 2 . A produção de água dessalinizada acumulada acompanhou as temperaturas no sistema, atingindo um valor de $2730,8 \mathrm{~mL} \mathrm{~m}^{-2}$. Observa-se que o aumento na produção de água dessalinizada é diretamente influenciado pela radiação solar e a temperatura alcançada pela água. Dessa forma, observa-se que a produção de água dessalinizada no período das $7 \mathrm{~h} 00 \mathrm{~min}$ às $17 \mathrm{~h} 00 \mathrm{~min}$ do experimento 2 foi um pouco maior do que o valor de $2596,1 \mathrm{~mL} \mathrm{~m}^{-2}$ obtido no experimento 1, e esta diferença volumétrica foi devido o valor da radiação do experimento 2 ter sido maior do que o experimento 1. Além disso, estes valores foram muito próximo ao valor reportado por Rajamanickam e Ragupathy (2012) para o dessalinizador solar de dupla inclinação. 


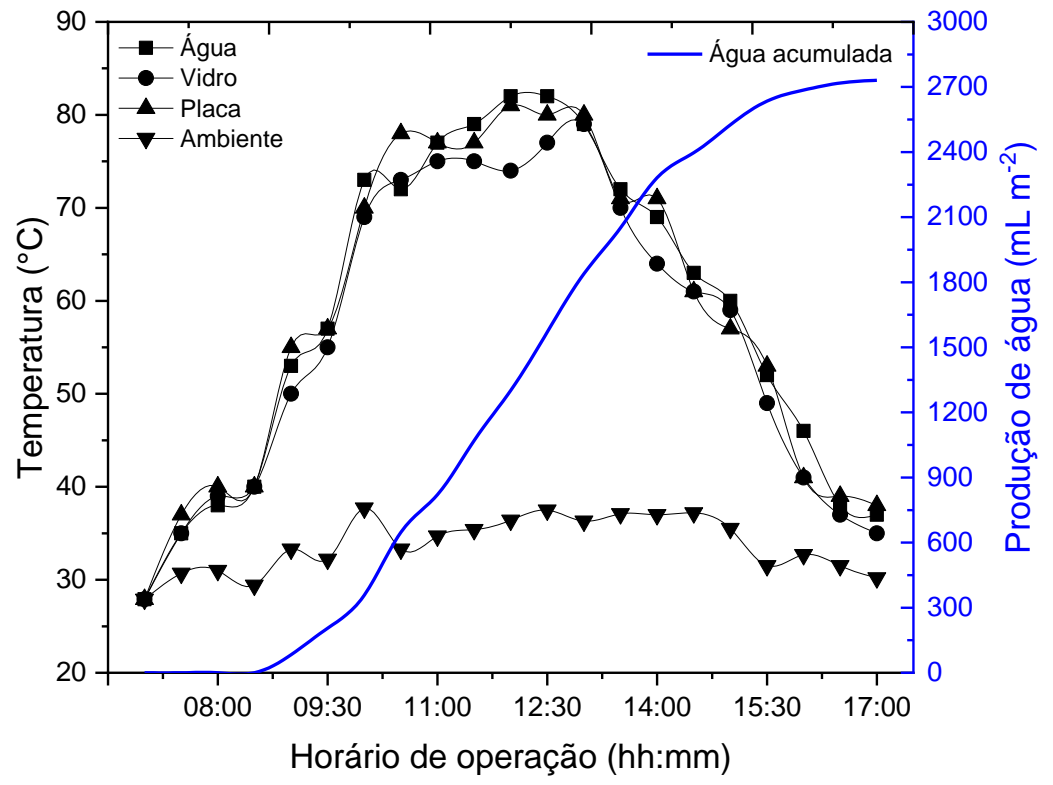

\subsection{Eficiência térmica do dessalinizador solar}

A evolução da eficiência térmica horária em função da radiação solar no dessalinizador para o experimento 1 está apresentada na Figura 6. Observa-se que a eficiência térmica horária acompanha o comportamento da radiação solar devido ao aumento dos perfis de temperatura no sistema. Uma eficiência máxima de $70,5 \%$ é alcançada às $16 \mathrm{~h} 00$ min mesmo com o decaimento da intensidade da radiação solar, e isso ocorre devido ao acúmulo de energia térmica anteriormente armazenada no interior do dessalinizador. Salinas-Freire, Pé-
rez-Ones e Rodríguez-Muñoz (2019) realizaram análises comparativas de dessalinizadores solares passivos e apreciaram que a eficiência teórica máxima atinge valores entre $25 \%$ e $63 \%$, enquanto os dados experimentais atingiram entre $1 \%$ e $45 \%$, valores ainda inferiores, ressaltando uma melhor eficiência térmica do dessalinizador solar.

Na Figura 7 está apresentada a evolução da eficiência térmica horária em função da radiação solar no dessalinizador para o experimento 2. A eficiência térmica horária variou entre $0,4 \%$ e $62,7 \%$ durante o tempo de operação do experimento.

Figura 6 - Eficiência térmica horária em função da radiação solar no experimento 1

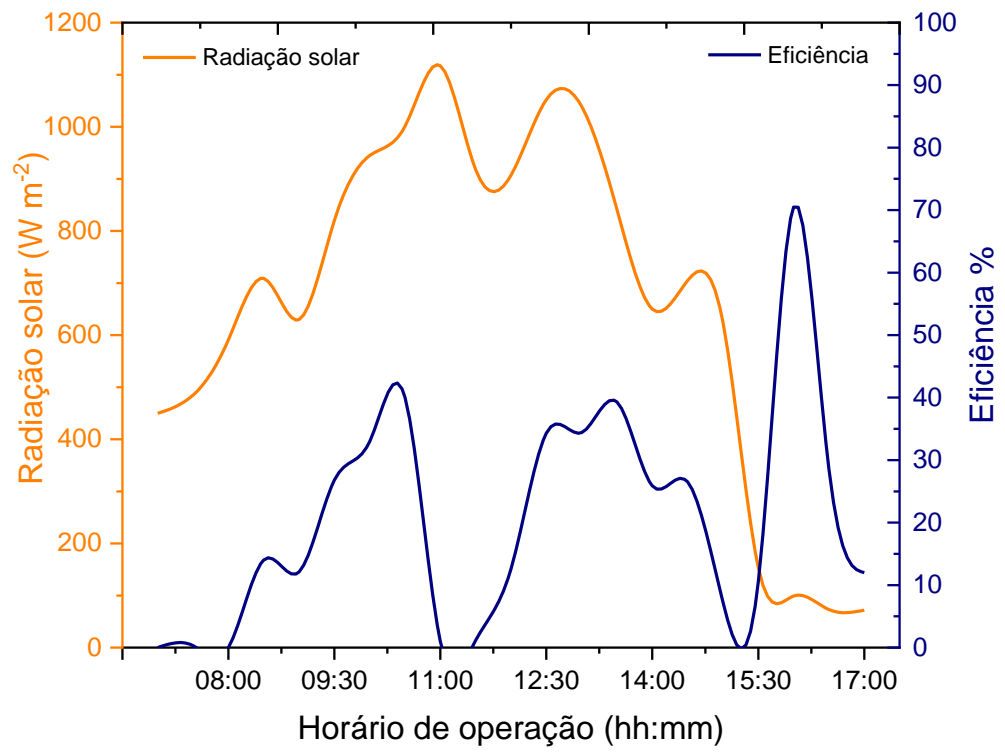


Figura 7 - Eficiência térmica horária em função da radiação solar no experimento 2

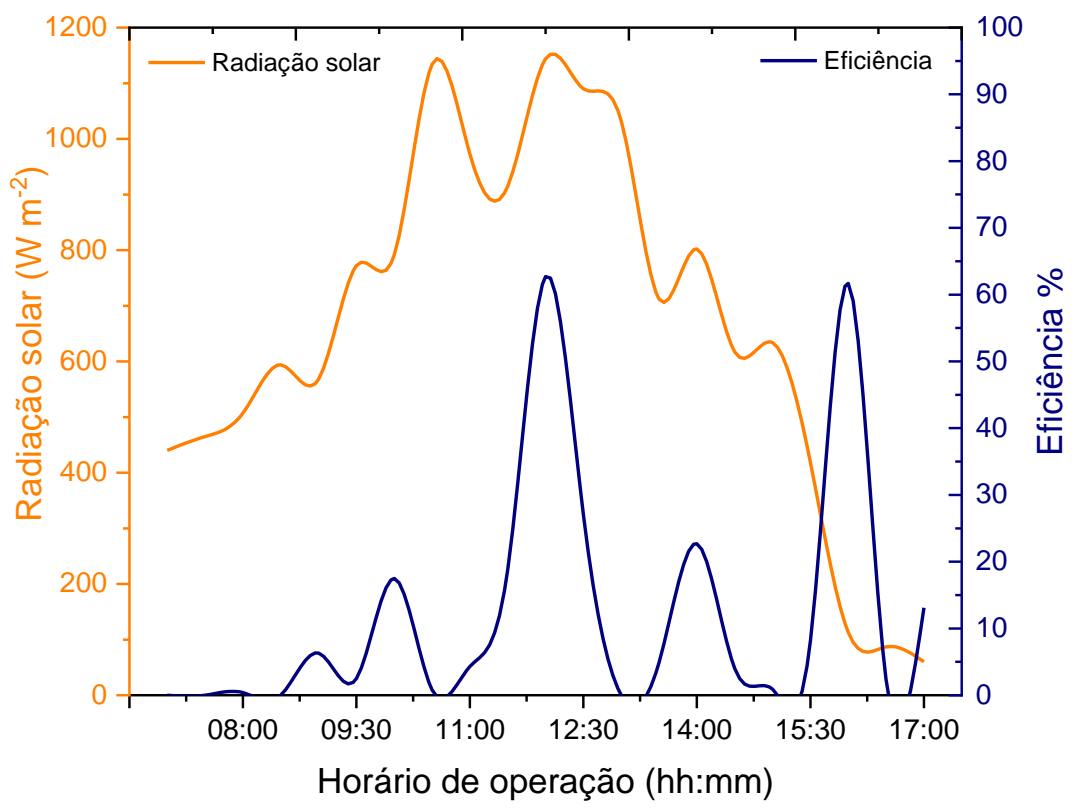

No estudo realizado por Mulftah, Sopian e Alghoul (2018) o dessalinizador escalonado antes e após a modificação com refletores, a eficiência térmica horária máxima relatada foi de $52,3 \%$ e 60,2\%, respectivamente, bem próximo ao encontrado nesse estudo. A eficiência térmica diária do experimento 1 foi de $21,67 \%$, enquanto do experimento 2 foi de $16,39 \%$. Comparando as eficiências encontradas no dessalinizador com absorvedor e condensador de pinos desenvolvido por Rabhi et al. (2017), no qual obteve, respectivamente, 21,93\% e $25,39 \%$, é possível analisar que os valores obtidos neste estudo se encontram dentro de uma faixa aceitável de eficiên cia, tornando o sistema viável para obtenção de água dessalinizada.

\subsection{Estudo da potabilidade da água}

Após verificar a produtividade de água tratada no dessalinizador solar, o presente estudo se deteve também a verificar a potabilidade da água doce gerada pelo sistema proposto. A Tabela 1 apresenta um comparativo entre a água salobra bruta e a água dessalinizada com relação aos parâmetros de potabilidade. Além disso, também são apresentados os valores máximos permitidos pela legislação vigente no país.

Tabela 1 - Parâmetros físico-químicos da água salobra e da água dessalinizada

\begin{tabular}{|c|c|c|c|}
\hline Parâmetro de controle & $\begin{array}{c}\text { Água } \\
\text { salobra }\end{array}$ & $\begin{array}{c}\text { Água } \\
\text { dessalinizada }\end{array}$ & V.M.P.* \\
\hline $\mathrm{pH}$ & 8,0 & 7,4 & $6,0-9,5$ \\
\hline Condutividade elétrica $\left(\mu \mathrm{Scm}^{-1}\right)$ & 8316,0 & 28,0 & - \\
\hline Cor aparente $(\mathrm{uH})$ & 6,7 & 3,5 & 15,0 \\
\hline Cloreto (mg Cl- L-1) & 2577,3 & 7,1 & 250,0 \\
\hline Dureza (mg $\left.\mathrm{CaCO}_{3} \mathrm{~L}^{-1}\right)$ & 360,0 & 50,0 & 500,0 \\
\hline Alcalinidade $\left(\mathrm{mg} \mathrm{CaCO}_{3} \mathrm{~L}^{-1}\right)$ & 28,0 & 2,0 & - \\
\hline Turbidez (NTU) & 0,6 & 0,5 & 5,0 \\
\hline Sódio (mg Na+ L-1) & 810,0 & 1,0 & 200,0 \\
\hline Potássio (mg K+ $\mathrm{L}^{-1}$ ) & 4,0 & 0,0 & - \\
\hline STD (mgL-1) & 4130,0 & 11,0 & 1000,0 \\
\hline
\end{tabular}

*V.M.P. = Valor Máximo Permitido segundo a RDC n 5, de 28 de setembro de 2017, Anexo XX

Os resultados obtidos das análises qualificaram o potencial hidrogeniônico da água como básico, devido à apresentação de um valor superior a 7 . Na amostra para a água bruta foi encontrado o pH 8,0 e após o processo de dessalinização o pH diminuiu para 7,39. Brito et al. (2020) analisaram águas de poços em comunidades rurais também no município de Juazeirinho - PB, e encontraram valores de $\mathrm{pH}$ na faixa de 7,5 a 7,8 , considerado de neutro a moderadamente alcalino. Comparando esses dados com a Portaria de Consolidação $\mathrm{n}^{\circ}$ 005/2017 do MS (BRASIL, 2017), que estabelece os índices 
ideais de $\mathrm{pH}$ entre 6,0 e 9,5, observa-se que as amostras apresentam valores dentro do padrão de potabilidade.

A condutividade elétrica determina a capacidade da água em conduzir a corrente elétrica na presença de substâncias dissolvidas que se dissociam em ânions e cátions, assim sendo exatamente proporcional à concentração iônica (LIBÂNIO, 2010). O valor encontrado foi de $8316 \mu \mathrm{S} \mathrm{cm} \mathrm{cm}^{-1}$ para a água bruta, e que foi superior ao encontrado por Silva et al. (2016) de $5140 \mu \mathrm{S} \mathrm{cm}^{-1} \mathrm{em}$ poço artesiano do Assentamento Belo Monte, município de Pedra Lavrada-PB. Com a aplicação da dessalinização foi possível observar uma redução de 99,67\% da condutividade elétrica na água. De acordo com dados da CETESB (2009) a baixa condutividade inferior a 200 HS $\mathrm{cm}^{-1}$ pode indicar água potável por apresentar concentrações baixas de sais dissolvidos. No presente estudo apenas a água obtida no processo de dessalinização apresentou nível inferior de $200 \mu \mathrm{S} \mathrm{cm}^{-1}$ de condutividade elétrica, sendo aceitável a qualidade da água para consumo humano para este parâmetro.

O valor obtido na análise de sólidos totais dissolvidos (STD) na água bruta foi de 4130,0 mg L-1, na qual encontra-se fora dos padrões exigidos pela legislação brasileira, que delimita valor máximo de $1000 \mathrm{mg} \mathrm{L}^{-1}$ para água potável. A concentração em excesso de STD pode oferecer risco, tornando a água desagradável ao paladar e o seu consumo pode causar o acúmulo de sais na corrente sanguínea, possibilitando a formação de cálculos renais (SANTOS e MOHR, 2013). Quanto ao valor obtido de STD da água dessalinizada foi de $11 \mathrm{mg} \mathrm{L}$ 1 , tendo uma redução de $99,73 \%$ de STD que estavam presentes na amostra bruta, e, portanto, o parâmetro atendeu o valor referenciado pela legislação vigente.

Os parâmetros de cor, turbidez, dureza e alcalinidade das amostras de água salobra e de água dessalinizada apresentaram-se dentro dos padrões de potabilidade de acordo com a Portaria de Consolidação n ${ }^{\circ}$ 005/2017 do MS (BRASIL, 2017) antes e após o processo de dessalinização.

Os cloretos estão presentes em quase todas as águas subterrâneas e são provenientes da dissolução de minerais, estando normalmente associado ao sódio (SILVA e MIGLIORINI, 2014). Logo, analisando a amostra de água bruta, observou-se níveis altíssimos de cloreto com 2577,3 $\mathrm{mg} \mathrm{L}^{-1}$, um valor 10 vezes maior que o permitido pela Portaria de Consolidação $n^{\circ}$ 005/2017 do MS (BRASIL, 2017) e valor superior ao encontrado por Silva et al. (2016) de 1370,3 mg $\mathrm{L}^{-1}$ em poço artesiano no município de Pedra Lavrada-PB. Entretanto, ao analisar a mesma água após o processo de dessalinização solar, obteve-se uma redução de 99,72\% de cloreto, resultado compatível com o parâmetro de potabilidade estabelecido pelo Ministério da Saúde (BRASIL, 2017).

Além disso, um dos parâmetros mais significativo foi o sódio, que apresentou na amostra de água bruta alto teor, no valor de $810,0 \mathrm{mg} \mathrm{L}^{-1} \mathrm{e}$, após o processo de dessalinização obteve um valor de 1,0 mg L-1, tendo uma redução de 99,88\% de sódio na água. Comparando esses dados com a Portaria de Consolidação $n^{\circ}$ 005/2017 do MS (BRASIL, 2017), que estabelece o valor máximo de $200 \mathrm{mg} \mathrm{L}^{-1}$ de sódio, observa- se que apenas a amostra de água dessalinizada apresenta valor dentro do padrão de potabilidade. No estudo de Cardoso et al. (2020), um dessalinizador tipo cascata foi desenvolvido, e analisaram águas de poços no município de Juazeirinho PB com valores de sódio na água salobra de 520,0 mg L-1, que pós-dessalinização, constataram valores baixos e próximos reportado neste estudo para fins de potabilidade.

Com relação ao parâmetro potássio, a Portaria de Consolidação $n^{\circ}$ 005/2017 do MS não estabelece limites em água de abastecimento humano. 0 potássio foi encontrado apenas na água bruta com concentração de 4,0 mg L-1 (Tabela 1). 0 potássio é um elemento importante para o corpo humano e, juntamente com o sódio, participam de trocas intracelulares (QUEIROZ e OLIVEIRA, 2018). Segundo dados da CETESB (2009), as concentrações de potássio em águas naturais não excedem $10 \mathrm{mg} \mathrm{L}^{-1}$, indicando que as águas bruta e dessalinizada do estudo encontram-se dentro do padrão esperado para esse elemento.

Devido aos baixos níveis de salinidade da água dessalinizada obtida, faz-se necessária a adição de sais minerais para adequá-la ao consumo humano de acordo com a Resolução da Diretoria Colegiada - RDC N³16, de 17 de outubro de 2019, do Ministério da Saúde e Agência Nacional de Vigilância Sanitária (BRASIL, 2019). Uma forma é misturar a água dessalinizada obtida com a água salobra utilizada. Por meio dessa mistura, a produção diária do dessalinizador solar é maior, atendendo a um maior número de pessoas. Ainda de acordo com a $\operatorname{RDC} n^{\circ} 316$, a água após o processo de dessalinização precisa conter o mínimo de $30 \mathrm{mg} \mathrm{L}^{-1}$ de sais e no máximo de $600 \mathrm{mg} \mathrm{L}^{-1}$ de sódio, e deve atender aos padrões de potabilidade estabelecidos pela Portaria de Consolidação $n^{\circ}$ 005/2017 do MS (BRASIL, 2017). Desse modo, para atender aos padrões de potabilidade, deve-se acrescentar na água dessalinizada um percentual de $0,9 \%$ do volume de água bruta, desde que a mesma se encontre dentro dos padrões micriobiológicos estabelecidos pela Portaria de Consolidação $n^{\circ}$ 005/2017 do MS (BRASIL, 2017).

\section{CONCLUSÕES}

O dessalinizador solar portátil tipo ondular com refletores de radiação integrados apresentou resultados eficientes na produção de água dessalinizada, atendendo alguns padrões de potabilidade de água vigente para consumo humano. Os níveis de incidência de radiação solar sobre o dessalinizador foram essenciais para o aumento dos perfis de temperatura e evaporação da água salobra, que promoveram o processo de dessalinização. Os resultados obtidos das análises físico-químicas das águas salobra e dessalinizada foram satisfatórios, apresentando valores de cloreto, sódio, STD entre outros após o processo de dessalinização, dentro dos valores máximos permitidos pela Portaria de Consolidação $n^{\circ}$ 005/2017 do MS, o que confirma a eficiência do dessalinizador solar para a obtenção de água dessalinizada. Portanto, foi possível concluir que o processo de dessalinização solar se configura uma boa alternativa para a produção de água dessalinizada para comunidades isoladas, em que a demanda de água não é elevada, e onde existe alta incidência de radiação solar. 


\section{AGRADECIMENTOS}

Os autores agradecem a Coordenação de Aperfeiçoamento de Pessoal de Nível Superior (CAPES) e ao Conselho Nacional de Desenvolvimento Científico e Tecnológico (CNPq) pela concessão das bolsas.

\section{REFERÊNCIAS}

AL-GARNI, A. Z. Productivity enhancement of solar still using water heater and cooling fan. Journal of solar energy engineering, v. 134, n. 3, 2012. https://doi.org/10.1115/1.4005760

ARUNKUMAR, T.; RAJ, K.; RUFUSS, D. D. W.; DENKENBERGER, D.; TINGTING, G.; XUAN, L.; VELRAJ, R. A review of efficient high productivity solar stills. Renewable and Sustainable Energy Reviews, v. 101, p. 197-220, 2019. https://doi.org/10.1016/j.rser.2018.11.013

BAIRD, R. B.; EATON, A. D.; RICE, E. W. Standard Methods for the Examination of Water and Wastewater. 1496 p. 23th edition. Washington, USA: American Public Health Association, 2017.

BOUZAID, M.; ANSARI, O.; TAHA-JANAN, M.; MOUHSIN, N.; OUBREK, M. Numerical Analysis of Thermal Performances for a Novel Cascade Solar Desalination Still Design. Energy Procedia, v. 157, p. 1071-1082, 2019. https://doi.org/10.1016/i.egypro.2018.11.274

BRASIL. Portaria de consolidação de $n^{\circ} 5$ de 28 de setembro de 2017 do Ministério da Saúde. Dispõe sobre os procedimentos de controle e de vigilância da qualidade da água para consumo humano e seu padrão de potabilidade.

BRASIL. Resolução da Diretoria Colegiada - RDC No 316, de 17 de outubro de 2019 do Ministério da Saúde e Agência Nacional de Vigilância Sanitária. Dispõe sobre os requisitos sanitários da água do mar dessalinizada, potável e envasada.

BRITO, Y. J. V.; CARDOSO, M. K. B.; SILVA, K. S. S.; SILVA, C. B.; MEDEIROS, K. M.; LIMA, C. A. P. Estudo experimental de um dessalinizador solar do tipo bandeja com dupla inclinação para potabilização de água no semiárido paraibano. Águas Subterrâneas, v. 34, n. 2, p. 156-165, 2020. https://doi.org/10.14295/ras.v34i2.29773

CAMPOS, B. L. O.; FRAGA, M. M. C.; COSTA, A. O. S.; JUNIOR, E. F. C. Análise do processo de dessalinização solar com ênfase no método de umidificação e desumidificação. Engenharia Sanitaria e Ambiental, v. 24, n. 5, p. 861-873, 2019. https://doi.org/10.1590/s1413-41522019177407

CARDOSO, M. K. B.; BRITO, Y. J. M.; SILVA, K. S. S.; SILVA, C. B.; MEDEIROS, K. M.; LIMA, C. A. P. et al. Dessalinizador solar do tipo cascata aplicado em poços artesianos no interior da Paraíba. Águas Subterrâneas, v. 34, n. 2, p. 135-142, 2020. https://doi.org/10.14295/ras.v34i2.29799

CETESB - Companhia Ambiental do Estado de São Paulo. Qua-

lidade das águas interiores no estado de São Paulo. São Paulo: CETESB. 44 p. 2009.

EL-AGOUZ, S. A. Experimental investigation of stepped solar still with continuous water circulation, Energy Convers. Manag v. 86, p. 186-193, 2014. https://doi.org/10.1016/j.enconman.2014.05.021

ESTAHBANATI, M. R. K.; AHSAN, A.; FEILIZADEH, M.; JAFARPUR, K.; ASHRAFMANSOURI, S-S.; FEILIZADEH, M. Theoretical and experimental investigation on internal reflectors in a singleslope solar still. Applied energy, v. 165, p. 537-547, 2016. https://doi.org/10.1016/i.apenergy.2015.12.047

FONSECA, F.; RODRÍGUEZ, J. C. R.; ACOSTA, F. F.; PERDOMO, E. M.; LOMBÁ, O. F. Software "SoftDest" y su Validación. RTQ, Santiago de Cuba, v. 40, n. 1, p. 68-80, abr., 2020.

INMET. Instituto Nacional de Meteorologia. Ministério da agricultura, pecuária e abastecimento. Brasília, DF: INMET, 2019. Disponível em: http://www.inmet.gov.br/portal/index.php? $r=$ home $/$ page \&page=sobre tempo. Acesso em: 03 fev. 2020.

LIBÂNIO, M. Fundamentos de qualidade e tratamento de água. 3. ed. Campinas, SP: Átomo, 2010.

MARINHO, F. J. L.; TAVARES, A. C.; SANTOS, S. A. D.; MARCOVICZ, F.; CRUZ, M. P.; SOUTO, E. A.; ROCHA, E. N. D. Destilador solar destinado a fornecer água potável para as famílias de agricultores de base familiar. Revista Brasileira de Agroecologia, v. 7, n. 3, p. 53-60, 2012.

MATRAWY, K. K.; ALOSAIMY, A. S.; MAHROUS, A.-F. Modeling and experimental study of a corrugated wick type solar still: comparative study with a simple basin type. Energy conversion and management, v. 105, p. 1261-1268, 2015. https://doi.org/10.1016/i.enconman.2015.09.006

MOLLAHOSSEINI, A.; ABDELRASOUL, A.; SHEIBANY, S.; AMINI, M.; SALESTAN, S. K. Renewable energy-driven desalination opportunities-A case study. Journal of environmental management, 239, p.187-197, 2019. https://doi.org/10.1016/j.jenvman.2019.03.044

MULFTAH, A. F.; SOPIAN, K.; ALGHOUL, M. A. Performance of basin type stepped solar still enhanced with superior design concepts. Desalination, v. 435, p. 198-209, 2018. https://doi.org/10.1016/i.desal.2017.07.017

OLIVEIRA, A. M.; DIAS, N. S.; FREITAS, J. J. R.; MARTINS, D. F. F.; RABELO, L. N. Avaliação físico-química das águas do processo de dessalinização de poços salobros e salinos em comunidades rurais do oeste potiguar. Águas subterrâneas, v. 31, n. $2, \quad$ p. 2017. https://doi.org/10.14295/ras.v31i2.28663

OMARA, O.; KABEEL, A. E.; ABDULLAH, A. S.; ESSA, F. A. Experimental investigation of corrugated absorber solar still with wick and reflectors. Desalination, v. 381, p. 111-116, 2016. https://doi.org/10.1016/j.desal.2015.12.001

OMARA, Z. M.; KABEEL, A. E.; ABDULLAH, A. S. A review of solar still performance with reflectors. Renewable and Sustainable Energy Reviews, v. 68, p. 638-649, 2017. https://doi.org/10.1016/i.rser.2016.10.031

QUEIROZ, T. M.; OLIVEIRA, L. C. P. Qualidade da água em comunidades quilombolas do Vão Grande, município de Barra do 
Bugres (MT). Eng. sanit. ambient, p. 173-180, 2018. https://doi.org/10.1590/s1413-41522018166375

RABHI, K.; NCIRI, R.; NASRI, F.; ALI, C.; BACHA, H. B. Experimental performance analysis of a modified single-basin singleslope solar still with pin fins absorber and condenser. Desalination v. 416, p. 86-93, 2017. https://doi.org/10.1016/i.desal.2017.04.023

RAJAMANICKAM, M. R.; RAGUPATHY, A. Influence of water depth on internal heat and mass transfer in a double slope solar still. Energy Procedia, v. 14, p. 1701-1708, 2012 https://doi.org/10.1016/j.egypro.2011.12.1155

RASHIDI, S.; RAHBAR, N.; VALIPOUR, M. S.; ESFAHANI, J. B. Enhancement of solar still by reticular porous media: experimental investigation with exergy and economic analysis. Applied Thermal Engineering, v. 130, p. 1341-1348, 2018. https://doi.org/10.1016/i.applthermaleng.2017.11.089

SALINAS-FREIRE, H. A.; PÉREZ-ONES, O.; RODRÍGUEZ-MUÑOZ, S. Límites termodinámicos a la productividad de los destiladores solares pasivos. Revista ION, v. 32, n. 1, p. 7-20, 2019. https://doi.org/10.18273/revion.v32n1-2019001
SANTOS, R. S.; MOHR, T. Saúde e qualidade da água: análises microbiológicas e físico-químicas em águas subterrâneas. $R e-$ vista Contexto \& Saúde, 13.24-25: 46-53, 2013.

SILVA, J. J. F.; MIGLIORINI, R. B. Caracterização das águas subterrâneas do aquífero furnas na região sul do estado de Mato Grosso. Geosciences= Geociências, v. 33, n. 2, p. 261-277, 2014.

SILVA, J. A. L.; MEDEIROS, M. C. S.; LIMA, V. L. A.; MARINHO, F. J. L.; AZEVEDODO, P. V.; UCHÔA, T. R.; OTONI, L. C. P. Obtenção de água potável a partir do uso da energia solar disponível na região do semiárido paraibano. Revista ESPACIOS. Vol. 37 ( ${ }^{\circ}$ 32), 2016.

SILVA, G. D. P.; SHARQAWY, M. H. Techno-economic analysis of low impact solar brackish water desalination system in the Brazilian Semiarid region. Journal of Cleaner Production, v. 248 , p. $119255, \quad 2020$. https://doi.org/10.1016/i.jclepro.2019.119255 